\title{
Genetic and serological heterogeneity of the supertypic HLA-B locus specificities Bw4 and Bw6
}

\author{
C. A. Müller ${ }^{1}$, G. Engler-Blum ${ }^{1}$, V. Gekeler ${ }^{2}$, I. Steiert ${ }^{1}$, E. Weiss ${ }^{3}$, and H. Schmidt ${ }^{1}$ \\ ${ }^{1}$ Medizinische Universitätsklinik und Poliklinik, Abteilung II, D-7400 Tübingen, Federal Republic of Germany \\ 2 Institut für Physiologische Chemie, D-7400 Tübingen, Federal Republic of Germany \\ ${ }^{3}$ Institut für Immunologie, D-8000 München 1, Federal Republic of Germany
}

\begin{abstract}
Gene cloning and sequencing of the $H L A-B$ locus split antigens B38 (B16.1) and B39 (B16.2) allowed localization of their subtypic as well as their public specificities HLA-Bw4 or -Bw6 to the $\alpha$-helical region of the $\alpha 1$ domain flanked by the amino acid positions 74-83. Comparison of their amino acid sequences with those of other HLA-B-locus alleles established HLA-Bw6 to be distinguished by Ser at residue 77 and Asn at residue 80 . In contrast, HLA-Bw4 is characterized by at least seven different patterns of amino acid exchanges at positions 77 and 80-83. Reactivity patterns of Bw4- or Bw6-specific monoclonal antibodies reveal two alloantigenic epitopes contributing to the HLA-Bw4 or -Bw6 specificity residing next to the region of highest diversity of the $\alpha 1$ domain.
\end{abstract}

\section{Introduction}

HLA class I antigens are polymorphic membrane glycoproteins with ubiquitous distribution on almost all nucleated cells. They bind peptides of processed antigens and present them to cytotoxic T lymphocytes (CTL; Germain 1986, Chen and Parham 1989). Initially, class I antigens controlled by the $H L A-A, B, C$ loci were differentiated by the reactivity patterns mainly of pregnancy alloantisera with individual cells. Development and use of specific monoclonal antibodies, as well as T-cell responses and biochemical analyses, revealed extensive structural heterogeneity of these molecules. HLA-A, B, C antigens were thus shown to express a variety of different antigenic determinants. Like the antigens of the $\mathrm{H}-2$ system in the mouse (summarized in Klein 1986), some of the HLA antigens are unique and define particular $H L A$ alleles as so-called private specificities, whereas others are termed supertypic or public specificities because they

Address correspondence and offprint requests to: C. A. Müller, Medizinische Universitätsklinik und Poliklinik, Abteilung II, OtfriedMüller-Strasse 10, D-7400 Tübingen, FRG. are shared by several allelic products of a single locus or even by molecules encoded by different $H L A$ loci. The earliest known supertypic HLA determinants were the HLA-Bw4 and -Bw6 specificities (van Rood 1962). Either of them is expressed together with a particular private specificity on a given HLA-B molecule (Ayres and Cresswell 1976). While the HLA-Bw4 determinant is found in addition on the $H L A-A$-locus antigens A24, A23, and A32 (Kostyu et al. 1980), the HLA-Bw6 public specificity is also present on the product of the $H L A$ $C$-locus allele $C w 3$ (Layet et al. 1985). Molecular variants of the Bw4 specificity have been reported based on the serological reactivity patterns of different Bw4-specific monoclonal antibodies (Müller et al. 1985a, Müller et al. 1982). Recent cloning and sequencing of a number of different $H L A$ alleles (Parham et al. 1988), as well as determination of the $X$-ray crystallographic structure of the HLA-A2 antigen (Bjorkman et al. 1987), has facilitated localization of various alloantigenic epitopes detected by monoclonal antibodies or recognized by CTL. Comparison of the primary structure of HLA-B and -A molecules (Wan et al. 1986), as well as exon shuffling experiments with $H L A-B 7$ and $-B 27$ genes (Toubert et al. 1988), recently suggested that the Bw4 and Bw6 specificities map to the first external domain, in particular to the amino acid residues 79-83. To characterize further genetic and structural heterogeneity of Bw4 and Bw6, we have exploited their association with the HLA-B antigens B38 and B39 which as subtypes of the HLA-B16 antigen are highly cross-reactive, but differ in the expression of these supertypic specificities.

\section{Materials and methods}

Cells. Peripheral blood leucocytes (PBL) were obtained from healthy donors after Ficoll hypaque density gradient centrifugation. HLA serotyping was performed by routine cytotoxicity assays using local standardized antisera, as well as antibodies of the Tenth International Histocompatibility Workshop. PBL of donor S with the HLA phenotype 
$\mathrm{A} 2, \mathrm{~A} 33, \mathrm{~B} 44, \mathrm{~B} 39, \mathrm{Cw} 5, \mathrm{Bw} 4, \mathrm{Bw6}$ and of donor $\mathrm{Z}$ with the HLA phenotype A26, Bw64, B38, Cw8, Bw4, Bw6 were selected for cloning of the $B 38$ and $B 39$ genes. All Epstein-Barr virus transformed B-cell lines were obtained from the Tenth International Histocompatibility Workshop cell-line panel with well-characterized HLA phenotype and genotype, and grown in RPMI 1640 medium supplemented with $10 \%$ fetal calf serum (FCS). L(tk ${ }^{-}$) cells, kindly provided by W. Summer (Yale University, New Haven, Connecticut), were maintained in Dulbecco's modified Eagle's medium (DMEM, Boehringer Mannheim, Mannheim, FRG) supplemented with $10 \%$ FCS.

Monoclonal antibodies. The monoclonal antibodies (mAbs) W6/32. HL (anti-HLA-ABCE heavy chain) and its inactive variant W6/32.HK were obtained from A. Ziegler (Institute of Immunology, Marburg, FRG; Barnstable et al. 1978). The antibody 4E (Yang et al. 1984) was kindly provided by S. Y. Yang (Sloan Kettering Institute, New York, USA). The Bw4-specific antibodies TÜ109 (Müller et al. 1985a) and TÜ48 (Müller et al. 1982) as well as the A2- and A28-specific mAb TÜ101 (Müller et al. 1983) from our laboratory have been described previously. The 2BC4 (Kandzia et al. 1981) and the SFR8-B6 antibodies (Radka et al. 1982) directed against HLA-Bw6 were generous gifts of $E$. Westphal (Institut für Hygiene, Kiel, FRG) and S. Radka (Duke University, Durham, USA), respectively. Further BW4- or BW6-specific monoclonal reagents, as well as A2- or A26-specific mAbs, were obtained during the Tenth International Histocompatibility Workshop.

Probes. $H L A-B$ genes were isolated by using $H L A-A$ and $-B$ locusspecific probes derived from the $H L A-B 7 \mathrm{CDNA}$ and the $H L A-A 2$ gene as described by Koller and co-workers (Koller et al. 1984). The HLA$B 27$ (Weiss et al. 1985) and -B51 genes (Pohla et al. 1989) have been described previously. The $H L A-C w 3$ gene (Sodoyer et al. 1984) was a gift of B. R. Jordan (CNRS, Marseille, France). The HLA-A2 and -B7 genes (Barbosa et al. 1982), as well as the $H L A-B 7$ cDNA probe (Sood et al. 1981), were kindly provided by S. Weissman (Yale University, New Haven, Connecticut).

DNA analysis. DNA extraction, restriction endonuclease mapping, and Southern blot hybridizations using specific ${ }^{32} \mathrm{P}$ multiprimed labeled probes under highly stringent conditions were carried out according to the procedures described earlier (Williams et al. 1987, Feinberg and Vogelstein 1983).

Isolation of genomic clones. Genomic DNA extracted from lymphocytes of donor S and Z was completely digested with Eco RI and electrophoresed on a preparative $0.7 \%$ agarose gel. DNA fragments (6 kbp long) eluted from the gels were cloned in the Eco RI site of lambda gt 11 (Promega, Madison, Wisconsin) as described previously (Williams et al. 1987). The two independent partial genomic libraries were screened by hybridization with $H L A-B 7$ cDNA and $H L A-A$ or $-B$ locus-specific probes under highly stringent conditions. Positive clones hybridizing with $H L A-B 7$ cDNA and the $H L A-B$ locus-specific probe were plaque purified.

Transfection of cloned genes. Cloned $H L A$ genes were cotransfected with the thymidine kinase gene into mouse $\mathrm{L}\left(\mathrm{tk}^{-}\right)$cells by the calcium phosphate precipitation method as described earlier (Wigler et al. 1979). As controls, $\mathrm{L}\left(\mathrm{tk}^{-}\right)$cells were transfected with the thymidine kinase gene only. After selection in HAT medium (DMEM supplemented with $15 \mu \mathrm{g} / \mathrm{ml}$ hypoxanthine, $1 \mu \mathrm{g} / \mathrm{ml}$ aminopterin, and $5 \mu \mathrm{g} / \mathrm{ml}$ thymidine), colonies were picked and grown in mass culture.

Immunofluorescence analysis. Indirect immunofluorescence labeling of PBL and transfectants was performed with the use of poly- and monomorphic monoclonal HLA-specific antibodies and evaluated on fluorescence-activated cell sorter (FACS) IV as previously described (Müller et al. 1985b).
Radioimmunoassay. Surface HLA expression of transfectants was analyzed by a quantitative radioimmunoassay using the monomorphic monoclonal antibodies $\mathrm{W} 6 / 32$. HL and $4 \mathrm{E}$, as well as the polymorphic monoclonal antibodies TÜ109 and 2BC4 as reported earlier (Schmidt et al. 1987).

Isoelectric focusing (IEF) analysis. Isoelectric focusing was carried out on HLA class I products immunoprecipitated with the monoclonal antibodies W6/32.HL or $4 \mathrm{E}$ from ${ }^{35} \mathrm{~S}$-labeled transfectants and PBL of donor $\mathrm{S}$ and $\mathrm{Z}$ according to the procedure described previously (Yang et al. 1984, Yang 1989). PBL were stimulated with phytohemagglutinin overnight, transfectants with mouse interferon for $24 \mathrm{~h}$ before labeling.

DNA sequencing. After restriction endonuclease mapping of recombinant clones, subcloning of appropriate fragments up to about $500 \mathrm{bp}$ was performed into pUC13. Supercoil DNA sequencing according to Chen and Seeburg (1985) was carried out by the dideoxy chain termination method (Sanger et al. 1977) using Sequenase TM (United States Biogenical Corporation, Fa. Renner, Dannstatt, FRG) or Taq polymerase (Stratagene, Heidelberg, FRG).

\section{Results}

Cloning of $H L A-B 38$ and $-B 39$ genes. $H L A-B 38(B w 4)$ and $H L A-B w 39(B w 6)$ genes were obtained from partial genomic libraries of two German Caucasian individuals who were serologically typed heterozygous for the supertypic determinants Bw4/Bw6. IEF analysis of immunoprecipitated HLA class I antigens and comparison with previously established band patterns of HLA-A, -B, $-C$ allelic products (Yang 1989) revealed that donor $S$ expressed the $H L A-B$-locus subtypes $B w 44.2(B w 4)$ $B 39(B 16.2 ; B w 6)$, whereas donor Z's genotype was $B w 64(B w 6), B 38(B 16.1 ; B w 4$; data not shown). On the basis of Southern blot hybridization of Eco RI-digested genomic DNA with the $H L A-B$ locus-specific probe, it appeared that $H L A-B$ genes were included in 6-kb fragments of both donors exclusively. From each of the two partial genomic libraries established from these fragments, four recombinant $\operatorname{lgt} 11$ clones which strongly hybridized with the $H L A-B$ locus-specific probe were selected for transfection of L(tk-) cells. The transfected cells were shown in radioactive binding assays with poly- and monomorphic monoclonal antibodies to express Bw4- or Bw6-positive HLA-B products (Table 1). No reactivity was seen with the monoclonal antibodies TÜ101 [anti-A2, A28; (Müller et al. 1983)] or Tenth International Histocompatibility workshop 2066 and $2067 \mathrm{mAbs}$ specific for A2 or A26, ruling out the possibility that these clones encoded $A 2$ or A26 of donor's $\mathrm{S}$ or $\mathrm{Z}$ lymphocytes (data not shown). The identity of the $H L A-B 38$ and $-B 39$, as well as of the $H L A-$ $B w 64$ genes, was further established by IEF analysis of the expressed, immunoprecipitated HLA class I molecules from the transfectants in comparison with the respective products from the donor's lymphocyts (data not shown). Weak binding of $4 \mathrm{E}$ and W6/32.HL, but not of TÜ109 or $2 \mathrm{BC} 4$, on $\mathrm{L}\left(\mathrm{tk}^{-}\right)$cells transfected with clone S1.1.a 
Table 1. Identification of the cloned genes after expression in mouse $\mathrm{L}$ cells by an indirect radioactive binding assay with the mAb W6/32.HL (common $H L A-A B C E)$, 4E (HLA-B and C), 2BC4 (HLA-Bw6), Tü109 (HLA-Bw4).

\begin{tabular}{|c|c|c|c|c|c|c|}
\hline \multirow{2}{*}{$\begin{array}{l}\text { Transfected } \\
\text { cell line }\end{array}$} & \multirow[t]{2}{*}{ Donor } & \multicolumn{4}{|c|}{ mAb Reactivity on transfected cells } & \multirow{2}{*}{$\begin{array}{l}\text { Expressed } \\
H L A \text { gene }\end{array}$} \\
\hline & & W6/32.HL & $4 \mathrm{E}$ & $2 \mathrm{BC} 4$ & Tü 109 & \\
\hline Z1a a3 & $\mathrm{Z}$ & $7579 *$ & 16734 & 27659 & 253 & $B 14$ \\
\hline $\mathrm{Z} 8 \mathrm{~b}$ a2 & $\mathrm{Z}$ & 3500 & 4485 & 5260 & 134 & $B 14$ \\
\hline $\mathrm{Z} 5 \mathrm{a}$ b2 & $\mathrm{Z}$ & 11637 & 11896 & 228 & 2426 & B38 \\
\hline S13b a3 & $\mathbf{S}$ & 14144 & 15701 & 20258 & 290 & $B 39$ \\
\hline S14a b1 & $S$ & 8725 & 7221 & 11297 & 148 & $B 39$ \\
\hline S1.1.a & $\mathrm{S}$ & 483 & 638 & 423 & 268 & $B 44 ? ?$ \\
\hline S2.1.c & $S$ & 830 & 986 & 340 & 260 & $B 44 ? ?$ \\
\hline BII3 & & 432 & 258 & 472 & 291 & none \\
\hline
\end{tabular}

* cpm (average of three triplicates).

BII3 is a cell line transfected with the thymidine kinase gene of herpes simplex, but not with an $H L A$ gene.

or $\mathrm{S} 2.1 . \mathrm{c}$ of donor $\mathrm{Z}$ suggested that these clones encoded HLA-Bw44.2.

Sequences of B38 and B39 genes. The exons encoding the first three extracellular domains of the $B 38$ and $B 39$ genes were sequenced (Fig. 1). The leader peptide of both genes was identical to that of $B 7$ (Biro et al. 1983). $H L A-B 38$ was found to differ from $H L A-B 39$ in only seven nucleotide substitutions confined to exon 2 encoding the $\alpha 1$ domain. From an overall comparison of their translated protein sequences with other known HLA class I proteins (Fig. 2), $H L A-B 39$ shows identity with $H L A$ $B 14$ in the $\alpha 1$ domain, whereas $H L A-B 38$ differs from $H L A-B 14$ at six positions between the residues 74-83. Within this region, $H L A-B 38$ is completely identical to $H L A-B 58$ (Ways et al. 1985), $B-51$ and $B-52$ (Hayashi et al. 1989). Within exon $3, H L A-B 38$ and $-B 39$ exhibit identical unique sequences at the codons $106,107,158,167$, and 168 in comparison with other known $H L A-A,-B, C$ genes. At codons 113 and/or 114, HLA-B38 and -B39 share nucleotides with $H L A-B 13$ (Zemmour et al. 1988), $-B 58$ (Ways et al. 1985), $-B 60,-B 40 *$ (Ways et al. 1987), $-B 14,-B 65,-B 42,-B 18$ (Parham et al. 1988), $-B 7.1$, and $B 7.2$ (Orr et al. 1979, López de Castro et al. 1979). The nucleotide sequence at codon 116 of $H L A-B 38$ and $-B 39$ is also identical to $H L A-B 14$ and $-B 65$ (Parham et al. 1988). At position $131, H L A-B 38$ and $-B 39$ differ from the consensus sequence (Parham et al. 1988) in a further nucleotide exchange producing serine instead of arginine, as demonstrated already in another group of HLA-B molecules (Parham et al. 1988). In all other positions of exon 3 , the cloned genes were identical to the consensus sequence shared by many $H L A-B$ alleles (Parham et al. 1988).

Genetic polymorphism of the Bw4 and Bw6 specificities. The sequence differences between HLA-B38 and -B39 were related to protein data of other HLA class I molecules to define the genetic basis of the serological polymorphism of the Bw4 and Bw6 and of the HLAB16-related subtypic specificities. The seven nucleotide exchanges between the Bw4-positive $H L A-B 38$ and the Bw6-positive $H L A-B 39$ genes lead to six amino acid substitutions between positions 74 and 83 (Figs. 1 and 2). At amino acid position 77 , as well as at positions $80-83$, HLA-B39 is identical to all other Bw6-positive HLA-B molecules, as well as $\mathrm{HLA}-\mathrm{Cw} 3$ which also carries the

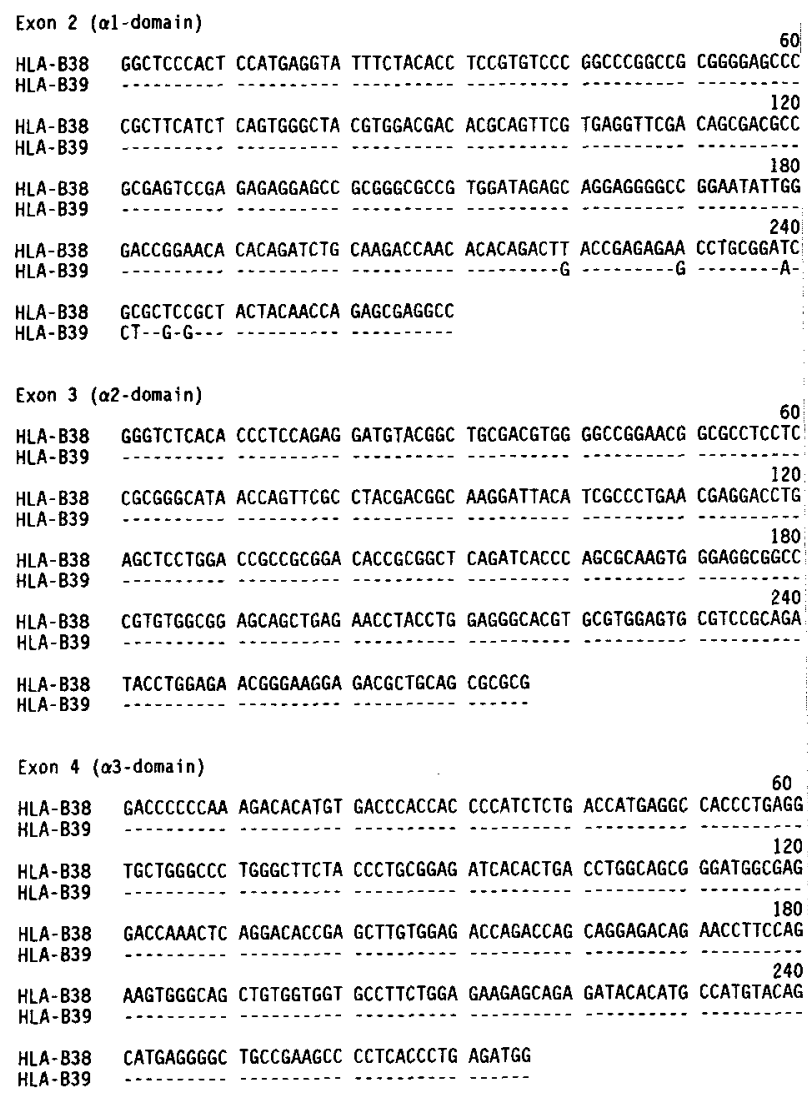

Fig. 1. DNA sequence of the second and third exons of the $H L A-B 38$ and $H L A-B 39$ genes. 


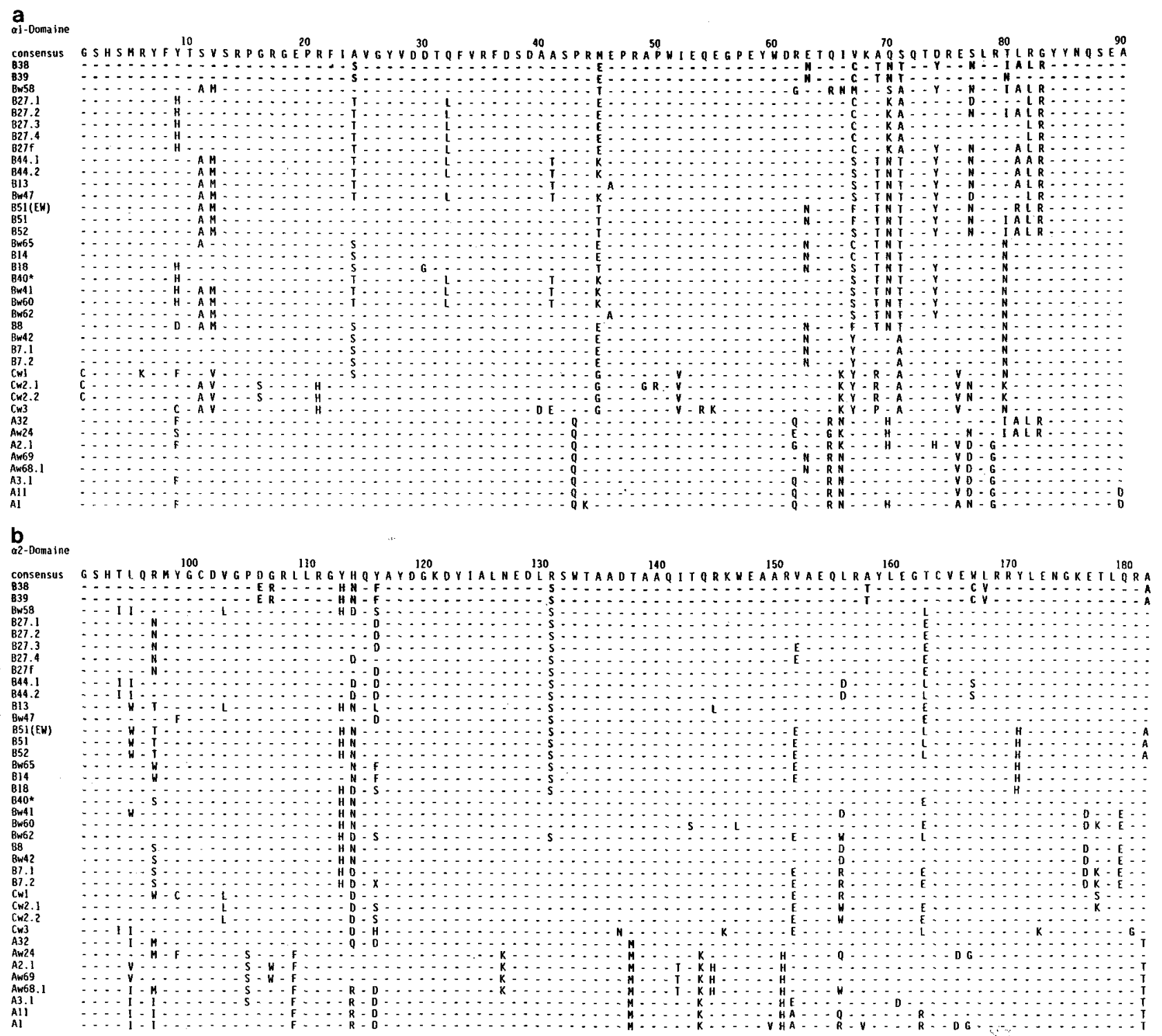

Fig. 2. Amino acid sequence comparison of HLA-B38 and HLA-B39 with other HLA-A, B,C molecules in the $\alpha 1$ and $\alpha 2$ domain. The dashed indicate identity with the consensus sequence derived from the sequences shown. The sequences were obtained from the following references: B27.1 (Weiss et al. 1985) and variants (Vega et al. 1986); B44.1 (Kottmann et al. 1986); B44.2 (Parham et al. 1988); B13 and B47 (Yang 1989); A1, Bw65, B14, B18, B41, B42 (Parham et al. 1988); Bw60, B40* (Ways et al. 1987); B8 (Parham et al. 1988); B7.1 and B7.2 (Cowan et al. 1987, López de Castro et al. 1979); Bw58 (Ways et al. 1985); A2.1 (Koller and Orr 1985); A24 (N'Guyen et al. 1985); A3.1 (Strachan et al. 1984); Al1 (Cowan et al. 1987); A32 (Wan et al. 1986); Cw3 (Sodoyer et al. 1984); Cw1, Cw2 (Güssow et al. 1987); B51 and B52 (Hayashi et al. 1989); B51EW and Bw62 (Pohla et al. 1989); Aw69 and Aw68 (Holmes et al. 1987).

Bw6 determinant. The sequence LRG at positions 81-83 is also shared by all known HLA-A allelic products. In contrast, HLA-B38 is homologous to HLA-B58, -B51, and -B52 at amino acid position 77, as well as in the sequence IALR at positions 80-83. All other Bw4-positive HLA-B as well as -A allelic products are identical only in arginine at residue 83 and differ at positions 77 and 80-82. Thus, Bw4-positive HLA class I molecules may carry TLLR, TRLR, TALR, TAAR at positions 80-83 and asparagine, serine, or aspartatic acid at residue 77 . Arginine at position 79 is shared by all HLA-B and -C molecules, but not by Bw4/Bw6-negative HLA-A molecules. The change of tyrosine in HLA-B38 to aspartic acid in HLA-B39 at position 74 is also found in other HLA-B or -C molecules independent of their expression of the Bw4 or Bw6 specificities and implies a charge difference of these molecules.

Serological polymorphism of the HLA-Bw4 or $-B w 6$ specificities. To correlate genetic with serological heterogeneity of the HLA-Bw4 and -Bw6 specificities, transfectants carrying defined $H L A$ class I genes, as well 
Table 2. Serological characterization of HLA-Bw4/Bw6 on transfectants and Tenth International Histocompatibility Workshop B-cell lines and correlation with amino acid sequence data of the $\alpha 1$ domain at residues 77 and $80-83$.

\begin{tabular}{|c|c|c|c|c|c|c|c|}
\hline \multirow[t]{3}{*}{ Cells } & \multirow[t]{3}{*}{$\begin{array}{l}\text { HLA } \\
\text { phenotype }\end{array}$} & \multicolumn{2}{|c|}{ Amino acid sequence } & \multicolumn{4}{|c|}{$\begin{array}{l}\text { Bw4 and Bw6 correlated reactivity of different monoclonal } \\
\text { antibodies }\end{array}$} \\
\hline & & \multirow[t]{2}{*}{77} & \multirow[t]{2}{*}{$80-83$} & \multicolumn{2}{|c|}{ Anti-Bw4 } & \multicolumn{2}{|c|}{ Anti-Bw6 } \\
\hline & & & & TÜ48 & TÜ109 & $2 \mathrm{BC} 4$ & SFR8.B6 \\
\hline \multicolumn{8}{|c|}{ Transfectants } \\
\hline $\mathrm{Z5}$ & B38(Bw4) & $N$ & IALR & ++ & + & - & - \\
\hline HII3 & $\mathrm{B} 27.1(\mathrm{Bw4})$ & $\mathrm{D}$ & TLLR & $+t$ & + & - & - \\
\hline III1 & $\mathrm{B} 51(\mathrm{EW})(\mathrm{Bw} 4)$ & $\mathrm{N}$ & TRLR & ++ & + & - & - \\
\hline $\mathrm{S} 13 \mathrm{~b}$ & B39(Bw6) & $\mathrm{S}$ & NLRG & - & - & ++ & ++ \\
\hline $\mathrm{Zla}$ & Bw64(Bw6) & $S$ & NLRG*** & - & - & ++ & ++ \\
\hline DII & $\mathrm{B} 7(\mathrm{Bw} 6)$ & $\mathrm{S}$ & NLRG & - & - & ++ & ++ \\
\hline GII3 & $\mathrm{Cw} 3(\mathrm{Bw6})$ & $S$ & NLRG & - & - & - & ++ \\
\hline $\mathrm{CII} 3$ & $\mathrm{~A} 2$ & $\mathrm{D}$ & TLRG & - & - & - & - \\
\hline \multicolumn{8}{|c|}{ B-cell lines } \\
\hline WS 9050 & $\mathrm{~B} 44.1^{* *}(\mathrm{Bw} 4)$ & $\mathrm{N}$ & TAAR*** & + & - & - & - \\
\hline WS 9001 & $\mathrm{~A} 24 . \mathrm{l}(\mathrm{Bw} 4)$ & $\mathrm{N}$ & IALR*** & ++ & - & - & - \\
\hline WS 9035 & $\mathrm{~A} 32(\mathrm{Bw} 4)$ & $S$ & $\mathrm{IALR}^{* * *}$ & ++ & - & - & - \\
\hline
\end{tabular}

Binding activity in an indirect immunofluorescence assay: ++ , strong binding; + , weak binding; - , no reactivity; **, IEF defined variants; ***, presumed sequence data according to published gene sequences derived from other cell lines.

as B-cell lines with serologically and immunochemically well-characterized HLA class I antigens, were analyzed for their reactivity with various Bw4- and Bw6-specific monoclonal antibodies (Table 2). Comparison of available protein sequence data with binding patterns of monoclonal reagents revealed that the mAb TÜ48 (Müller et al. 1982) reacted with all tested cells expressing the HLA-Bw4 determinant. Sequence variability in positions 77 and 80-82 appeared to correlate with variability in binding activity of TÜ48. However, the mAb TÜ109 (Müller et al. 1985a) only recognized Bw4 ${ }^{+}$HLA-B antigens except B44.1. This antibody did not react with HLA-A molecules in spite of shared amino acid sequences at positions 77 and 80-83. The Bw6-specific antibody 2BC4 (Kandzia et al. 1981) reacted only with the transfected cell lines expressing $\mathrm{Bw}^{+}{ }^{+}$HLA-B molecules, whereas the antibody SFR8-B6 (Radka et al. 1982) also recognized HLA-Cw3.

\section{Discussion}

Primary structure of the HLA-B split antigens B38 and B39 was determined to identify the amino acid substitutions responsible for the Bw4 and Bw6 specificities. HLAB38 and -B39 are serologically difficult to distinguish by their private epitopes, but are clearly dissimilar in the Bw4 determinants. Previous comparison of HLA sequences (Parham et al, 1988, Wan et al. 1986) and exon shuffling experiments (Toubert et al. 1988) suggested positions
79-83 of the $\alpha 1$ domain to generate the Bw4 and Bw6 determinants. In this study, amino acid substitutions at positions 77 , as well as at positions $80-83$, are shown to contribute to the serologically defined Bw4 and Bw6 specificities and to correlate with reactivity patterns of monoclonal antibodies and alloantisera revealing heterogeneity and different epitopes of these antigens.

As has been shown for other serologically highly cross-reactive subtypes of HLA antigens, HLA-B38 and -B39 are very similar in their amino acid sequences, revealing only six amino acid differences within a limited region of high polymorphism in the $\alpha 1$ domain. When compared with other defined HLA molecules (Parham et al. 1988), B39 and B38 reveal unique sequences only in the $\alpha 2$ domain. According to the X-ray crystallographic structure of HLA-A2, the specific positions 106 and 107 are possibly situated on a loop outside the antigen binding site, and amino acid 167 at the $\alpha 2$-helical region is most likely involved in peptide binding. Positions 158 and 168 probably interact with the $\mathrm{T}$-cell receptor (Bjorkman et al. 1987). The complete identity of exon 2 and shared substitutions of exon 3 indicate that $H L A-B 39$ and $-B 14$ could be derived from a common ancestor by a process involving intrallelic exchange events and point mutations, as has been suggested for other HLA alleles (Parham et al. 1988). No serological cross-reactivity between B14 and B39, with the exception for the Bw6 epitope, has been observed; thus, the corresponding allotypic reagents may preferentially be directed against epitopes located on the 
$\alpha 2$ domain. Since $H L A-B 38$ shares nucleotides with $H L A$ $B 58$ (Ways et al. 1985), -B51, and -B52 (Hayashi et al. 1989 ) at codons $74-83$, it could have been generated in one step from $B 39$ by a single exchange event in which for example $H L A-B 58,-B 51$, or $-B 52$ donated another DNA segment encompassing codons 74-83. HLA-B39 which shares the entire $\alpha 1$ domain with $H L A-B 14$, could thus be the older of the two genes. Alternatively, $H L A$ $B 38,-B 39$, and $-B 14$ could have diverged simultaneously from a common ancestor by several steps of exchange events or point substitutions.

As the DNA segment flanked by codons 74 and 83 is the only region of the polymorphic $\alpha 1$ and $\alpha 2$ domains in which $H L A-B 38$ and $-B 39$ are different from each other, both subtypic epitopes, as well as the public determinants Bw4 or Bw6 on these molecules must be encoded within this area. The amino acid sequence SLRNLRG of HLAB39 between residues 77 and 83 correlates completely with Bw6 of all other known HLA-B and -C antigens. According to the amino acid sequences, Bw6 is distinguishable from other HLA-A, - B, -C molecules only by the simultaneous presence of serine at position 77 and asparagine at position 80 . In comparison, the HLA-Bw4 specificity could be related in HLA-B38 to the amino acid substitution asparagine at position 77 and the sequence IALR at residues 80-83. Similar substitutions, most likely generated by interlocus exchange processes, have already been found in the HLA-A molecules A32, and A24 carrying the Bw4 determinant ( $W$ an et al. 1986), and were also shown to code for Bw4 in the HLA-B58 (Ways et al. 1985), -B51, -B52 (Hayashi et al. 1989), and -B27.2 (Vega et al. 1986) molecules. The same polymorphic Bw4-related substitutions have also been observed in chimpanzees' $B$-locus antigens (Mayer et al. 1988, Lawlor et al. 1988) and therefore may predate divergence of human and chimpanzees MHC products. In other HLA$B$ molecules, alternative sequences between residues 79 to 83 were previously claimed to also be associated with the Bw4 determinant (Wan et al. 1986). Except for B44.1, these HLA-B molecules share the amino acids leucine and arginine at residues 82 and 83 with HLA-B38, but differ from $\mathrm{Bw} 4^{-}$HLA-A or Bw6 ${ }^{+}$HLA-B antigens at positions 77 and 80-81. Thus, in contrast to HLA-Bw6, at least seven different patterns of the amino acid sequence between positions 77 and 83 could be related to HLABw4. Rearrangement of small elements of sequences through gene conversion or intra-allelic exchange events, of which an example could be NLR found at positions 77-79 in Bw4 and at residues 80-82 in Bw6, in addition to point mutations, most likely have been involved in the generation of amino acid sequence variation associated with these public HLA-B specificities.

Variable amino acid sequences are likely to also account for the serological differences of the HLA-Bw4 and -Bw6 specificities (Müller et al. 1985a, Müller et al. 1982,
Layet et al. 1985). The observed weak correlation coefficients of Bw4- versus Bw6-specific alloantisera and monoclonal antibodies (Arnaiz-Villena et al. 1989) appear to reflect the genetic variability of these public specificities. Reactivity patterns of monoclonal antibodies on transfectants or B-cell lines allow differentiation of two alloantigenic epitopes associated with $\mathrm{Bw} 4$ formed by the $\alpha$ helix of the $\alpha 1$ domain between residues 77 and 83 . One epitope which is suggested to contact the T-cell receptor according to the $\mathrm{X}$-ray crystallographic structure of HLA-A2 is shared by all $\mathrm{Bw} 4^{+}$HLA-B antigens, as well as by the HLA-A molecules A24, and A32, and is recognized by the Bw4-specific antibody TÜ48. This epitope has also been defined by alloantisera (Kostyu et al. 1980). Binding of TÜ48 most likely involves interaction, particularly with the amino acids leucine and asparagine, at residues 82 and 83 which are shared by all $\mathrm{Bw} 4^{+}$HLA-A and -B antigens. The other Bw4 epitope is only present on HLA-B molecules and is discriminated by antibodies like TÜ109. Reactivity of this antibody may rely on a particular protein conformation induced at the $\alpha$-helical region by different amino acids at residues 77 , 80,81 , and 82 . This is suggested by selective binding of TÜ109 to $\mathrm{Bw} 4^{+}$HLA-B, but not $-\mathrm{A}$, molecules inspite of amino acid sequence variation, and could also explain the lack of reactivity with HLA-Bw44.1, exhibiting a specific Bw4-related amino acid sequence N, TAAR at these positions. According to the differential reactivity pattern of the antibodies SFR8-B6 and 2BC4 on transfectants, the Bw6 specificity could also include two epitopes. One is most likely recognized by the antibody SFR8-B6 directed against $\mathrm{Bw}^{+}$HLA-B and $-\mathrm{C}$ molecules, whereas the other one may be differentiated by $2 \mathrm{BC} 4$ selectively binding to HLA-B antigens. SFR8-B6 appears to interact predominantly with amino acid residues $80-83$, whereas $2 \mathrm{BC} 4$ seems to react particularly with amino acids at positions 80-77. Conformational changes of the 2BC4-defined epitope in HLA-Cw3 through amino acid substitutions in the immediate neighboring positions (i.e., exchange of valine in HLA-Cw3 for glutamic acid at position 76 in HLA-B molecules) could explain lack of reactivity of $2 \mathrm{BC} 4$ with HLA-Cw3. Thus, both public specificities HLA-Bw4 and -Bw6 appear to be characterized by one epitope distant from amino acid segment 62-76 with greatest sequence diversity of the $\alpha 1$ domain, as well as by another epitope next to this area. Reactivity of the mAbs TÜ109 and 2BC4 indicate that the three-dimensional structure of the latter epitope may be influenced by amino acid substitutions in the region of high diversity. The subtypic epitope of HLA-B38 and $-\mathrm{B} 39$, which can be differentiated from the Bw4 or Bw6 specificity by specific alloantisera, is most likely formed by the amino acid exchange at position 74 . It seems to be spatially distinct from the public specificities Bw4 and Bw6 in these molecules, whereas in other HLA-B antigens 
such as the B27 variants, overlapping of public and private epitopes, may occur, as is suggested by the reactivity pattern of specific mAbs like TM1 (Thurau et al. 1989). Therefore, recognition of this epitope by $\mathrm{Bw} 4-$ or Bw6-specific antisera may depend on similar conformation, but not neccessarily on identity of the amino acid sequence.

Acknowledgments. We thank Dr. H. J. Bühring for performing FACS analysis on the transfected cell lines. This work was supported by the Deutsche Forschungsgemeinschaft, Sonderforschungsbereich 120, projects $A 3, A 7$, and $D 4$. All recombinant DNA work was approved by the BGA, Berlin (FRG).

\section{References}

Arnaiz-Villena, A., Belvedere, M., Decary, F., Fotino, M., Heise, E., Hogan, V., Martinetti, M., Müller, C., Richiardi, P., and Vicario, J. L.: HLA-Bw4 and Bw6. In B. Dupont (ed.): Immunobiology of HLA 1989, Springer Verlag, New York, in press, 1989

Ayres, J. and Cresswell, P.: HLA-B specificities and w4, w6 specificities are on the same polypeptide. Eur $J$ Immunol 6: 794-799, 1976

Barbosa, J. A., Karmack, M.E., Biro, P. A., Weissman, S. M., and Ruddle, F. H.: Identification of human genomic clones coding the major histocompatibility antigens HLA - A2 and HLA - B7 by DNA - mediated gene transfer. Proc Natl Acad Sci USA 79: $6327-6331,1982$

Barnstable, C. J., Bodmer, W. F., Brown, G., Galfree, G., Milstein, C., Williams, A.F., and Ziegler, A.: Production of monoclonat antibodies to group A erythrocytes, HLA and other human cell surface antigens - new tools for genetic analysis. Cell 14: 9-20, 1978

Biro, P. A., Pan, J., Sood, A. K., Kole, R., Reddy, V. B., and Weissman, S.M.: Sequences of human repetitive DNA, nonalpha-globin genes, and major histocompatibility locus genes. Part III: the major histocompatibility complex. Cold Spring Harbor Symp Quant Biol 42: 1082-1086, 1983

Bjorkman, P. S., Sapes, M. A., Samraoui, B , Bennett, w. S., Strominger, J.L., and Wiley, D. C.: Structure of the human class I histocompatibility antigen. HLA-A2. Nature 329: 506-512, 1987

Chen, B. P. and Parham, P.: Direct binding of influenca peptides to class I molecules. Nature 337: 743-745, 1989

Chen, E. Y. and Seeburg, P. H.: Supercoil sequencing: a fast simple method for sequencing plasmid DNA. DNA 4: 165-170, 1985

Cowan, E. P., Jelachich, M. L., Biddison, W. E., and Coligan, J. E.: DNA sequence of HLA-A11: remarkable homology with HLA-A3 allows identification of residues involved in epitopes recognized by antibodies and T cells. Immunogenetics 25: 241-250, 1987

Feinberg, A. P. and Vogelstein, B.: A technique for radiolabeling DNA restriction endonuclease fragments to high specific activity. Anal Biochem 132: 6-13, 1983

Germain, R. N.: The ins and outs of antigen processing and presentation. Nature 322: 687-689, 1986

Güssow, D., Rein, R. S., Meijer, I., de Hood, W., Seemann, G. H. A., Hochstenbach, F. M., and Ploegh, H. L.: Isolation, expression, and the primary structure of $H L A-C w l$ and $H L A-C w 2$ genes: evolutionary aspects. Immunogenetics 25: 313-322, 1987

Hayashi, H., Ennis, P. D., Ariga, H., Salter, R. D., Parham, P., Kano, K., and Takiguchi, M.: HLA-B51 and HLA-Bw52 differ by only two amino acids which are in helical region of the $\alpha 1$ domain. $J$ Immunol 142: 306-311, 1989

Holmes, N., Ennis, P., Wan, A. M., Denney, D. W., and Parham, P.: Multiple genetic mechanisms have contributed to the generation of the HLA-A2/A28 family of class I MHC molecules. J Immunol 139: 936-941, 1987

Kandzia, J., Anderson, M. J.D., and Müller-Ruchholtz, W.: Cell seperation by antibody-coupled magnetic microspheres and their application in conjunction with monoclonal HLA-antibodies. $J$ Cancer Res Clin Oncol 101: 165-170, 1981

Klein, J.: The Natural History of the Major Histocompatibility Complex. pp. 279-280, Springer-Verlag, Berlin, Heidelberg, 1986

Koller, B.H. and Orr, H.T.: Cloning and complete sequence of an HLA-A2 gene: analysis of two HLA-A alleles at the nucleotide level. I Immunol 134: 2727-2733, 1985

Koller, B. H., Sidwell, B., DeMars, R., and Orr, H. T.: Isolation of HLA locus-specific DNA probes from the 3 '-untranslated region. Proc Natl Acad Sci USA 81: 5175-5178, 1984

Kostyu, D. D., Cresswell, P., and Amos, D. B.: A public HLA antigen associated with HLA-A9, Aw32 and Bw4. Immunogenetics 10: $433-442,1980$

Kottmann, A. H., Seemann, G. H. A., Guessow, H.D., and Rooș, M. H.: DNA sequence of the coding region of the HLA-B44 gene. Immunogenetics 23: 396-400, 1986

Lawlor, D. A., Ward, F. E., Ennis, P. D., Jackson, P., and Parhann. P.: HLA-A and B polymorphisms predate the divergence of humans and chimpanzees. Nature 335: 268-271, 1988

Layet, C., Delovitch, T., Ferrier, P., Caillol, D. H., Jordan, B. R. and Lemonnier, F. A.: Expression of an HLA-Bw6-related specificity by the HLA-Cw3 molecule. Immunogenetics $21: 469-478,1985$

López de Castro, J. A., Orr, H. T., Robb, J. R., Kostyk, T. G., Mann, D. L., and Strominger, J. L.: Complete amino acid sequence of a papain-solubilized human histocompatibility antigen. HLA-B7. 1. Isolation and amino acid composition of fragments and of tryptic and chymotryptic peptides. Biochemistry 18: 5704-5711, 1979

Mayer, W. E. Jonker, M., Klein, D., Ivanyi, P., Van Seventer, G, and Klein, J.: Nucleotide sequences of chimpanzee MHC class I alleles: evidence for trans-species mode of evolution. EMBO $J_{i, 2}$ : 2765-2774, 1988

Müller, C., Ziegler, A., Müller, G., Schunter, F., and Wernet, P.: Monoclonal antibody (Tue 48) defining alloantigenic class I determinants specific for HLA-Bw4 and HLA-Aw23, -Aw24 as well as -Aw32. Hum Immunol 5: 269-281, 1982

Müller, C., Liangru, S., Schneider, M., Ziegler, A., and Wernet, P.: A cytotoxic monocional IgM antibody (Tü 101) directed against an antigenic determinant shared between the HLA-A allospecificities A2 and A28. Hum Immunol 6: 189-197, 1983

Müller, C., Herbst, H., Uchanska-Ziegler, B., Ziegler, A., Schunter, F., Steiert, I., Muller, C., and Wernet, P.: Characterization of a monoclonal anti-Bw4 antibody (Tü 109): evidence for similar epitopes on the Bw4 and Bw6 antigens, Hum Immunol 14: 333-349; $1985 \mathrm{a}$

Müller,, C., Ziegler, A., Muller, C., Hadam, M., Waller, H.D., Wernet, P., and Müller, G.: Divergent expression of HLA $\mathrm{DC} / \mathrm{MB},-\mathrm{DR}$, and $-\mathrm{SB}$ region products on normal and pathological tissues as detected by monoclonal antibodies. Immunobiology 169 228-249, 1985b

N'Guyen, C., Sodoyer, R., Trucy, J., Strachan, T., and Jordan, B. R.: The $H L A-A w 24$ gene: sequence, surroundings and comparison with the HLA-A2 and HLA-A3 genes. Immunogenetics 21: 479-489. 1985

Orr, H. T., López de Castro, J. A., Lancet, D., and Strominger, J. L. Complete amino acid sequence of a papain-solubilized human histocompatibility antigen, HLA-B7.2. Sequence determination and search for homologies. Biochemistry 18: 5711-5720, 1979

Parham, P., Lomen, C. E., Lawlor, D. A., Ways, J. P., Holmes, N., Coppin, H. L., Salter, R. D., Wan, A. M., and Ennis, P. D.: Nature of polymorphism in HLA-A, -B, and -C molecules. Proc Natl Acad Sci USA 85: 4005-4009, 1988

Pohla, H., Kuon, W., Tabaczewski, P., Doerner, C., and Weiss, E. H. 
Allelic variation in HLA-B and HLA-C sequences and the evolution of the HLA-B alleles. Immunogenetics 29: 297-307, 1989

Radka, S. F., Kostyu, D. D., and Amos, D. B.: A monocional antibody directed against the HLA-Bw6 epitope. J Immunol 128: 2804-2806, 1982

Sanger, F., Nicklen, S., and Coulson, A. R.: DNA sequencing with chain termination inhibitors. Proc Natl Acad Sci USA 74: 5463-5467, 1977

Schmidt, H., Forsthuber, T., B, Bühring, H. J., and Müller, C.: Differential expression of the HLA-B7 and the HLA-A2 gene in transfected mouse $\mathrm{L}(\mathrm{tk}$-)cells after stimulation by mouse interferon. Immunobiology 174: 51-66, 1987

Sodoyer, R., Damotte, M., Delovitch, T. L., Trucy, J., Jordan, B. R., and Strachan, $T$.: Complete nucleotide sequence of a gene encoding a functional human class I histocompatibility antigen (HLA-Cw3). EMBO J 3: 879-885, 1984

Sood, A. K., Pereira, D., and Weissman, S. M.: Isolation and partial nucleotide sequence of a cDNA clone for human histocompatibility antigen HLA-B by use of an oligodeoxynucleotide primer. Proc Natl Acad Sci USA 78: 616-620, 1981

Strachan, T., Sodoyer, R., Damotte, M., and Jordan, B. R.: Complete nucleotide sequence of a functional class I HLA gene, HLA-A3: implications for the evolution of HLA genes. EMBO J 3: 887-894, 1984

Thurau, S. R., Wildner, G., Kuon, W., Weiss, E. H., and Riethmüller, G.: Expression and immunogenicity of HLA-B27 in high transfection recipient P815: a new method to induce monoclonal antibodies directed against HLA-B27. Tissue Antigens, in press, 1989

Toubert, A., Raffoux, C., Boretto, J., Sire, J., Sodoyer, R., Thurau, S. R., Amor, B., Colombani, J., Lemonnier, F. A., and Jordan, B. R.: Epitope mapping of HLA-B27 and HLA-B7 antigens by using intradomain recombinants. J Immunol 141: 2503-2509, 1988

van Rood, J.J.: Leucocyte Grouping: A Method and its Application, $\mathrm{Ph}$. D. thesis, Leiden University, Leiden, The Netherlands, 1962

Vega, M. A., Bragadōं, R., Ivanyi, P., Pelaez, J. L., and López de Castro, J. A.: Molecular analysis of a functional subtype of HLAB27. A possible evolutionary pathway for HLA-B27 polymorphism. J Immunol 137: 3557-3565, 1986
Wan, A. M., Ennis, P., Parham, P., and Holmes, N.: The primary structure of HLA-A32 suggests a region involved in formation of the Bw4/Bw6 epitopes. J Immunol 137: 3671-3674, 1986

Ways, J.P., Coppin, H. L., and Parham, P.: The complete primary structure of HLA-Bw58. J Biol Chem 260: 11924-11933, 1985

Ways, J.P., Lawlor, D. A., Wan, A.M., and Parham, P.: A transposable epitope of HLA-B7, B40 molecules. Immunogenetics 25: $323-328,1987$

Weiss, E. H., Kuon, W., Doerner, C., Lang, M., and Riethmüller, G.: Organization, sequence and expression of the HLA-B27 gene: a molecular approach to analyze HLA and disease associations. Immunobiology 170: 367-380, 1985

Wigler, M., Pellicer, A., Silverstein, S., Axel, R., Urlaub, G., and Chasin, L.: DNA-mediated transfer of the adenine phosphoribosyltransferase locus into mammalian cells. Proc Natl Acad Sci USA 76: 1373-1376, 1979

Williams, S. R., Gekeler, V., Mclvor, R. S., and Martin, D. W.: A human purine nucleoside phosphorylase deficiency caused by a single base change. I Biol Chem 262: 2332-2338, 1987

Yang, S. Y.: Assignment of HLA-A and HLA-B antigens for the reference panel of B-lymphoblastoid cell lines detected by one dimensional isoelectric focusing (1D-IEF) gel electrophoresis. In B. Dupont (ed.): Immunobiology of HLA 1989, Springer Verlag, New York, in press, 1989

Yang, S. Y., Morishima, Y., Collins, N. H., Alton, T., Pollack, M. S., Yunis, E. J , and Dupont, B.: Comparison of one-dimensional IEF patterns for serologically detectable HLA-A and B allotypes. Immunogenetics 19: 217-231, 1984

Zemmour, J., Ennis, P. D., Parham, P., and Dupont, B.: Comparison of the structure of $H L A-B w 47$ to $H L A-B 13$ and its relationship to 21-hydroxylase deficiency. Immunogenetics 27: 281-287, 1988

Received April 28, 1989; revised version received June 20, 1989. 